\title{
Mobile phone apps for clinical decision support in pregnancy: a scoping review
}

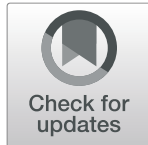

Jenny Carter ${ }^{*} \mathbb{D}$, Jane Sandall, Andrew H. Shennan and Rachel M. Tribe

\begin{abstract}
Background: The use of digital technology in healthcare has been found to be useful for data collection, provision of health information and communications. Despite increasing use of medical mobile phone applications (apps), by both clinicians and patients, there appears to be a paucity of peer-reviewed publications evaluating their use, particularly in pregnancy. This scoping review explored the use of mobile phone apps for clinical decision support in pregnancy. Specific objectives were to: 1. determine the current landscape of mobile phone app use for clinical decision support in pregnancy; 2. identify perceived benefits and potential hazards of use and 3. identify facilitators and barriers to implementation of these apps into clinical practice.

Methods: Papers eligible for inclusion were primary research or reports on the development and evaluation of apps for use by clinicians for decision support in pregnancy, published in peer-reviewed journals. Research databases included Medline, Embase, Psycholnfo, the Cochrane Database of Systematic Reviews and the online digital health journals JMIR mHealth and uHealth. Charting and thematic analysis was undertaken using NVivo qualitative data management software and the Framework approach.
\end{abstract}

Results: After screening for eligibility, 13 papers were identified, mainly reporting early stage development of the mobile app, and feasibility or acceptability studies designed to inform further development. Thematic analysis revealed four main themes across the included papers: 1. acceptability and satisfaction; 2. ease of use and portability; 3. multi-functionality and 4. the importance of user involvement in development and evaluation.

Conclusions: This review highlights the benefits of mobile apps for clinical decision support in pregnancy and potential barriers to implementation, but reveals a lack of rigorous reporting of evaluation of their use and data security. This situation may change, however, following the issue of FDA and MHRA guidelines and implementation of UK government and other international strategies. Overall, the findings suggest that ease of use, portability and multi-functionality make mobile apps for clinical decision support in pregnancy useful and acceptable tools for clinicians.

Keywords: Mobile applications, mHealth, Digital healthcare, Decision support systems, clinical, Decision support techniques

\section{Background}

The use of digital technology in healthcare has been recent and rapid and the advantages of mHealth, i.e. digital health technologies that utilize mobile phones, is seen as a natural progression [1]. Recent UK Government policy recognises value of digital health technology and encourages its integration [2]. Mobile technology has been found to be useful for data collection, provision of health

\footnotetext{
* Correspondence: jenny.carter@kcl.ac.uk

Department of Women and Children's Health, School of Life Course Sciences, Faculty of Life Sciences and Medicine, King's College London, London, UK
}

information and communications, particularly in lower and middle income countries, where mobile phones are very common [3-5]. An increasing body of evidence suggests mHealth interventions can improve outcomes and health service utilization [5-7]. One of the particular advantages of mobile phone applications (apps) is that they can be updated regularly, ensuring information is based on current evidence, and they are so readily accessible [8].

Mobile phone health apps are widely used by clinicians as well as patients. A survey of UK medical students 
$(n=257)$ and junior doctors $(n=131)$ carried out in 2011 found a high level of smart phone ownership (79\%, $203 / 257$ and $75 \%, 98 / 131$, respectively) and mobile app usage (76\%, 155/203 and $72 \%, 71 / 98$, respectively) with both groups expressing an interest in the development of additional apps to enhance their education and professional practice [9]. As technology has moved on in recent years, this is likely to have increased. A more recent survey of 197 Californian obstetrics and gynaecology doctors found that $95 \%$ used mobile apps in the clinical setting [10].

There are concerns, however, that without official validation and regulation some medical apps may produce erroneous results and lead to incorrect, inappropriate or even dangerous decisions [11]. In 2015, in recognition of the growing number of medical apps in use, the USA's regulatory body the Food and Drugs Administration (FDA) issued guidance [12]. This guidance stipulates that if a mobile app is defined as a medical device it will be regulated in the same way as other medical devices. In the UK, the Medicines and Healthcare products Regulatory Agency (MHRA) also considers and regulates medical mobile apps providing they meet the regulatory body's definition of a medical device [13].

Despite an increasing use of medical mobile phone apps in healthcare, by both clinicians and patients, there appears to be a paucity of peer-reviewed professional journal publications evaluating their use [14]. We decided to undertake a scoping review in order to identify papers providing insights that could inform development of mobile apps for clinical decision support in pregnancy. Specific objectives were to: 1 . determine the current landscape of mobile phone apps use for decision support or risk assessment by clinicians in pregnancy care; 2 . identify perceived benefits and potential hazards of use in clinical practice and 3. identify facilitators and barriers to implementation of these apps into clinical practice.

\section{Methods}

Inclusion and exclusion criteria were decided upon prior to initiating a database search and are listed in Table 1. We chose to focus on clinical decision support tools delivered through mobile phone apps, as opposed to other means e.g. clinical guidelines and decision trees. We also wanted to explore those used by clinicians, and therefore excluded apps used solely by pregnant women. The research databases used in the search included: Medline, Embase, PsychoInfo and the Cochrane Database of Systematic Review, with search terms and limits used for each database listed in Table 2. Reference lists and citing articles were also reviewed for other potentially relevant papers. In addition to these research databases, the online journals JMIR mHealth and uHealth, which have a
Table 1 Inclusion and exclusion criteria for the scoping review

\begin{tabular}{ll}
\hline Inclusion & Exclusion \\
\hline $\begin{array}{l}\text { Mobile phone applications } \\
\text { (apps) for decision support }\end{array}$ & $\begin{array}{l}\text { Decision aids not utilizing } \\
\text { mobile app technology, e.g. } \\
\text { or risk assessment in }\end{array}$ \\
pregnancy & $\begin{array}{l}\text { clinical guidelines/models/ } \\
\text { Apps for data collection or } \\
\text { delivery of information/health } \\
\text { promotion }\end{array}$ \\
& Statistical prediction models \\
Primary research or report of & Literature review \\
app development and & Study protocols \\
evaluation published in peer & Commentaries or editorials \\
reviewed journals & \\
App for use by clinicians or & App for use by pregnant \\
both clinicians and pregnant & women only \\
women & \\
\hline
\end{tabular}

specific focus on digital health, were also searched for papers reporting on pregnancy, labour or birth. After removal of duplicates, the database and JMIR journals search produced a total of 909 articles for screening. Review of the titles and abstracts identified 774 of these to be ineligible based on the inclusion criteria, leaving 135 papers for full text review. Of these, only 13 were eligible for inclusion, with 122 being excluded for the reasons shown in the PRISMA flow diagram (Fig. 1).

A formal review of quality was not undertaken because this was not a systematic review with the aim of establishing the efficacy of an intervention. Charting and thematic analysis was carried out using NVivo qualitative data management software (version. 11) and Framework Analysis [15]. Characteristics of the papers and the apps they describe are shown in Table 3. These include a description of the report or study design, setting, participants and time period, area of pregnancy focus and app characteristics. The main findings and conclusions reported by the authors were explored using thematic analysis.

\section{Results}

Characteristics of the papers included in the review

Details of the 13 included papers are shown in Table 3. Of the included papers, one [16] reported the reliability of a clinical decision support tool for calculating risk of preterm birth. The majority $(n=10)$ described early development of the mobile app with results of feasibility, usability studies and/or satisfaction studies [17-26]. Two reported results of studies evaluating maternity care projects in which the app was a central component of care delivery $[27,28]$.

Seven papers reported on studies or projects based in low and middle income countries, including Africa and Guatemala [17, 20, 24-28]. Two were based in the UK $[16,21]$, one in Spain and Italy [23] and one in USA [22]. In two papers the location of the project was 
Table 2 Search terms and limits for the scoping review

\begin{tabular}{|c|c|c|c|c|}
\hline & Search term & & Search term & Limit \\
\hline $\begin{array}{l}\text { Medline } \\
(n=598)\end{array}$ & $\begin{array}{l}\text { Pregnancy OR Exp Labour, } \\
\text { Obstetric OR } \\
\text { Labour OR } \\
\text { Premature Birth OR } \\
\text { Obstetric Labor, Premature } \\
\text { OR preterm.mp }\end{array}$ & AND & $\begin{array}{l}\text { mHealth.mp OR mobile } \\
\text { application.mp OR } \\
\text { Exp Mobile Applications } \\
\text { OR smart phone.mp } \\
\text { OR Exp Smartphone } \\
\text { OR Decision aid\$.mp } \\
\text { OR Risk assessment tool\$.mp } \\
\text { OR Predictive model.mp OR } \\
\text { App.mp }\end{array}$ & $\begin{array}{l}\text { Papers published between } 2007 \text { (when the iPhone } \\
\text { and first mobile apps were available) and June 2018; } \\
\text { Humans }\end{array}$ \\
\hline $\begin{array}{l}\text { Embase } \\
(n=187)\end{array}$ & $\begin{array}{l}\text { Pregnancy OR Exp Labour, } \\
\text { Obstetric OR } \\
\text { Labour OR } \\
\text { Premature Birth OR } \\
\text { Obstetric Labor, Premature } \\
\text { OR preterm.mp }\end{array}$ & AND & $\begin{array}{l}\text { mHealth.mp OR mobile } \\
\text { application.mp OR } \\
\text { Exp Mobile Applications } \\
\text { OR smart phone.mp } \\
\text { OR Exp Smartphone } \\
\text { OR Decision aid\$.mp } \\
\text { OR Risk assessment tool\$.mp } \\
\text { OR Predictive model.mp } \\
\text { OR App.mp }\end{array}$ & $\begin{array}{l}\text { Papers published between } 2007 \text { (when the iPhone and } \\
\text { first mobile apps were available) and June 2018; Humans; } \\
\text { Full text (as large number, } n=479 \text {, of abstract only } \\
\text { references were returned) }\end{array}$ \\
\hline $\begin{array}{l}\text { Psychinfo } \\
(n=61)\end{array}$ & $\begin{array}{l}\text { Pregnancy OR Exp Labour, } \\
\text { Obstetric OR } \\
\text { Labour OR } \\
\text { Premature Birth OR } \\
\text { Obstetric Labor, Premature } \\
\text { OR preterm.mp }\end{array}$ & AND & $\begin{array}{l}\text { mHealth.mp OR mobile } \\
\text { application.mp OR } \\
\text { Exp Mobile Applications } \\
\text { OR smart phone.mp } \\
\text { OR Exp Smartphone } \\
\text { OR Decision aid\$.mp } \\
\text { OR Risk assessment tool\$ } \\
\text { mp OR } \\
\text { Predictive model.mp } \\
\text { OR App.mp }\end{array}$ & $\begin{array}{l}\text { Papers published between } 2007 \text { (when the iPhone and } \\
\text { first mobile apps were available) and June 2018; Humans }\end{array}$ \\
\hline $\begin{array}{l}\text { Cochrane Database of } \\
\text { Systematic Reviews } \\
(n=46)\end{array}$ & $\begin{array}{l}\text { Pregnancy: tl, ab, kw } \\
\text { (including word variations) }\end{array}$ & AND & $\begin{array}{l}\text { mHealth OR decision aid } \\
\text { OR risk assessment tool } \\
\text { OR smart phone } \\
\text { OR mobile phone }\end{array}$ & No limits \\
\hline $\begin{array}{l}\text { JMIR mHealth and } \\
\text { uHealth } \\
(n=43)\end{array}$ & $\begin{array}{l}\text { Pregnancy OR Labour OR } \\
\text { Labor OR Birth }\end{array}$ & AND & $\begin{array}{l}\text { Risk } \\
\text { OR } \\
\text { Decision }\end{array}$ & No limits \\
\hline
\end{tabular}

Exp explode, m.p keyword search, $\$$ wildcard symbol, $t$ t title, $a b$ abstract, $k w$ keyword

unclear, however one of the corresponding authors was based in Korea [18] and the other in Germany [19]. All were published between 2014 and 2017: four in 2014; three in 2015; four in 2016 and two in 2017.

Four papers reported on apps focusing on preeclampsia $[17,19,20,26]$. Three of these, however, all referred to the same project, Pre-eclampsia Integrated Estimate of Risk (PIERS) [17, 20, 26]. Gestational diabetes was the focus for two papers $[21,23]$. The aims of the maternity care projects were to increase the number of births in a health facility in Zanzibar [27] and to improve access to maternity care for women in Ghana [28]. The pregnancy focus of each of the remaining five papers were: metabolic syndrome [18]; weight and blood pressure monitoring [22]; identification of fetal compromise [24]; antenatal depression [25] and preterm birth [16].

Thematic analysis of the main findings and conclusions as reported by the authors

Theme 1: acceptability and satisfaction

All papers reporting on acceptability, feasibility, usability and/or satisfaction were generally positive, both with the mobile app being evaluated, and also with the care it was designed to support. This was demonstrated by direct questioning and evaluation tools, but also by increased patient engagement with, for example, compliance with self-monitoring $[7,21,23]$. Increased confidence of health providers, enhanced positive relationships and trust in the professionals and feelings of support and safety were also reported [18, 21, 22, 27]. Validation of data and monitoring readings were often a feature of the app, and this was recognised by clinicians as a valuable improvement in care [17, 24]. Additionally, apps appeared to help clinicians identify priorities and they recognized the potential for the system to be time saving. The automatic transfer of data to electronic central databases or health records was also identified as a useful mechanism which could save clinicians' time as they could remotely review the data in advance of the patient's hospital appointment [23, 28]. Alerts systems were utilised in some apps to remind patients of, for example, appointments, medication, and monitoring $[21,22]$, or alert remote clinicians who could respond with advice, either directly to the patient or their local care givers [21, 24]. 


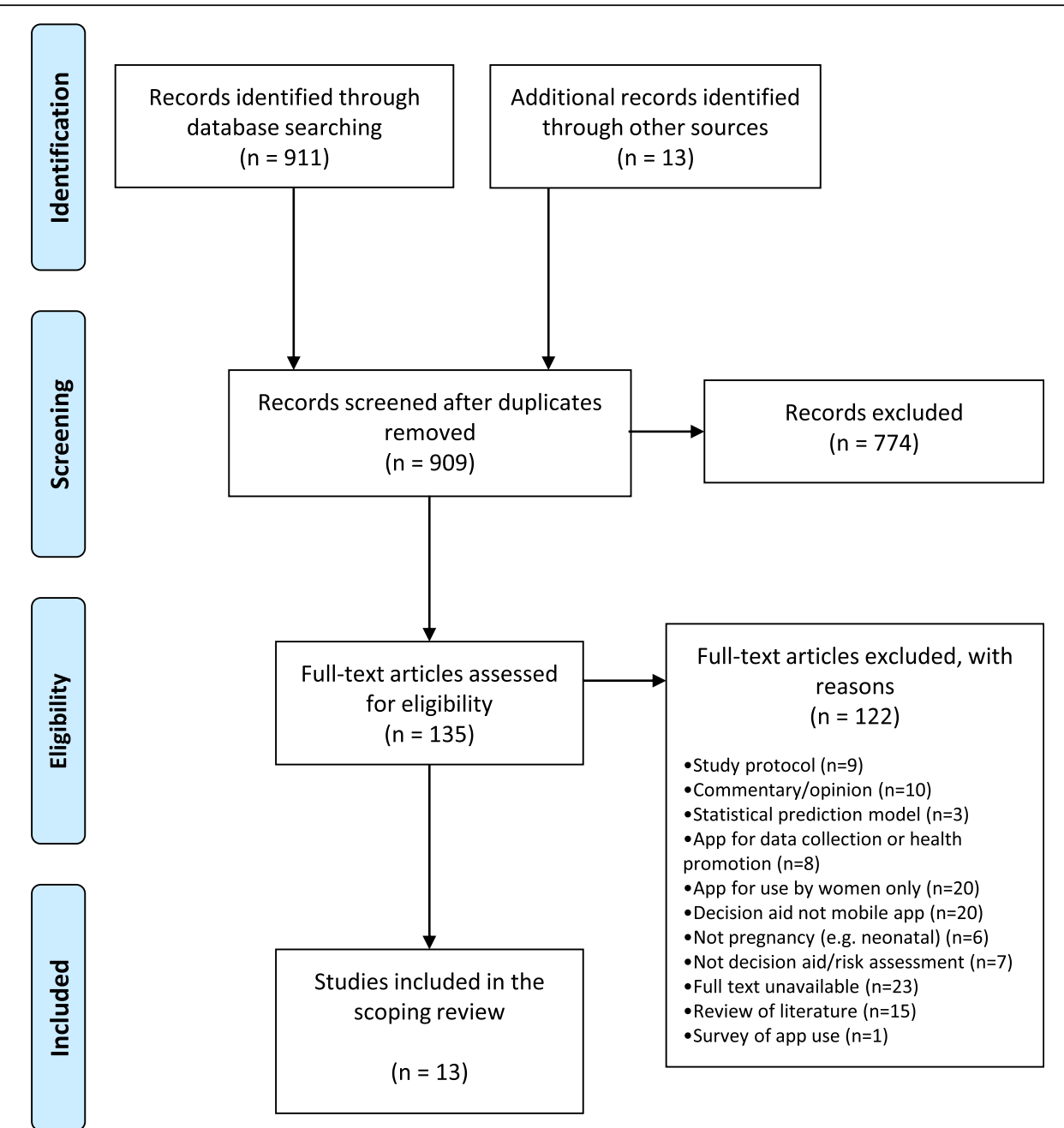

Fig. 1 PRISMA 2009 Flow Diagram of results of literature search

\section{Theme 2: ease of use and portability}

Most medical app users were familiar with smart phones, and the benefit of portability was regarded as a great asset [22, 27]. Some users reported problems which were often related to the phone's features, e.g. difficulties with entering data on a small mobile phone screen and the need for scrolling [17, 20]. Adaptation of features such as reducing the need for scrolling by having fewer data on each form, training and on-phone manuals were used to address these issues in later stages of app development $[18,24]$.

With the relative low cost of smartphones and convenience in terms of weight and size, along with the increasing connectivity to mobile networks, mobile apps appear to be accepted as an excellent opportunity for improving healthcare, particularly for those in low resource settings. One reason, proposed by a number of authors of the papers included in this review, is that less educated health care staff can be trained in providing front-line care using devices that are easy to use, with internal validation and warning alerts, with the added benefit of support from remote experts [24-26].

\section{Theme 3: multiple functionality}

The versatility and multi-functionality of smartphones appeared to be an important issue in the papers reviewed. As decision support tools, mobile apps can utilize statistical prediction models or decision trees and make recommendations for action based on input of individual risk factors and test results $[16,17,23]$. In addition to decision support, however, most apps (10/ 13) were also used for data collection, communication, or both. Other apps also incorporated Bluetooth internet connectivity with other devices: pulse-oximetry [20, 24]; blood glucose monitors [21, 23]; blood pressure monitors [22, 23]; digital weighing scales [22] and fetal Doppler devices [24]. One mobile app utilized the smartphone's own camera for processing pictures used 


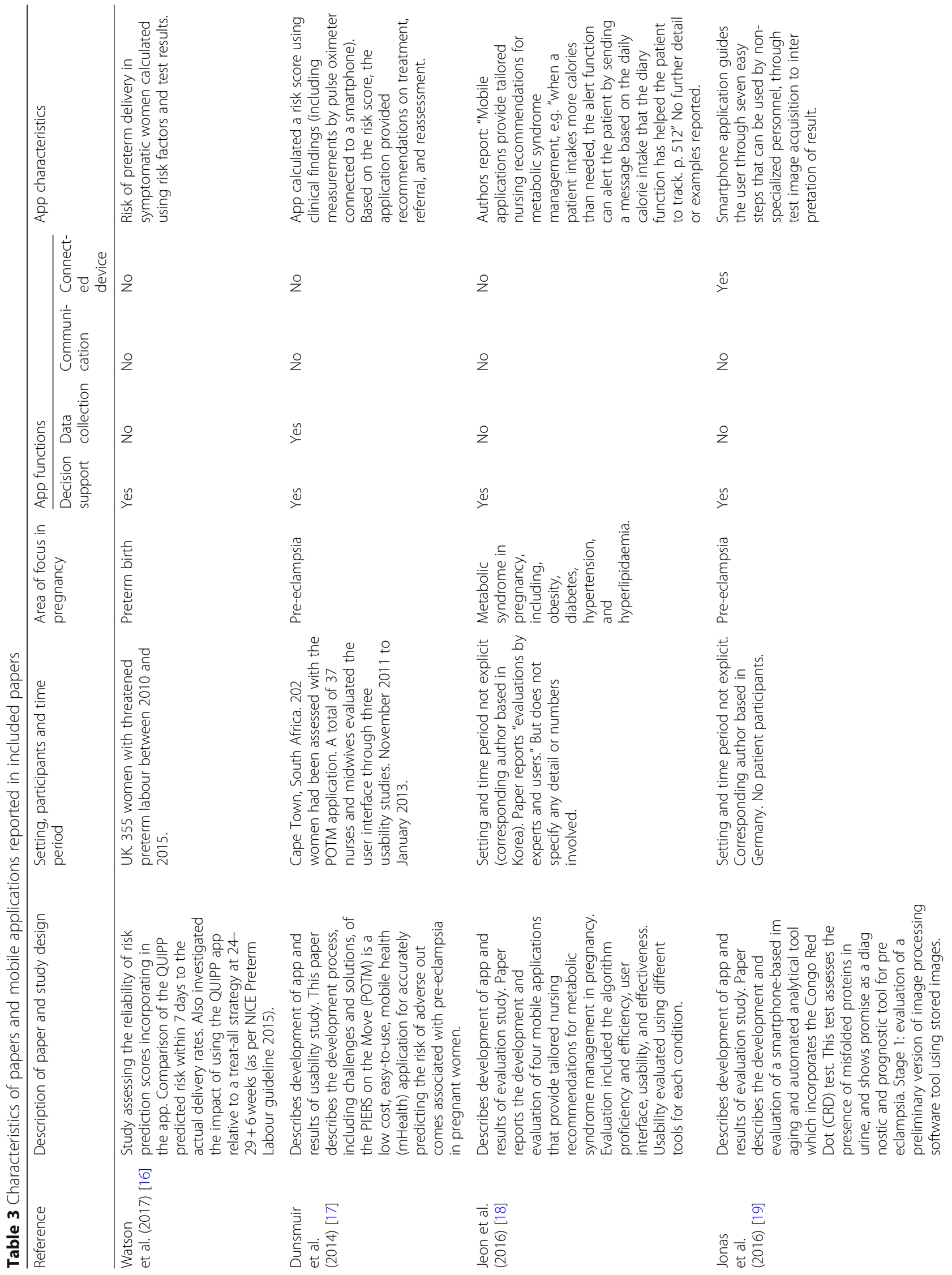




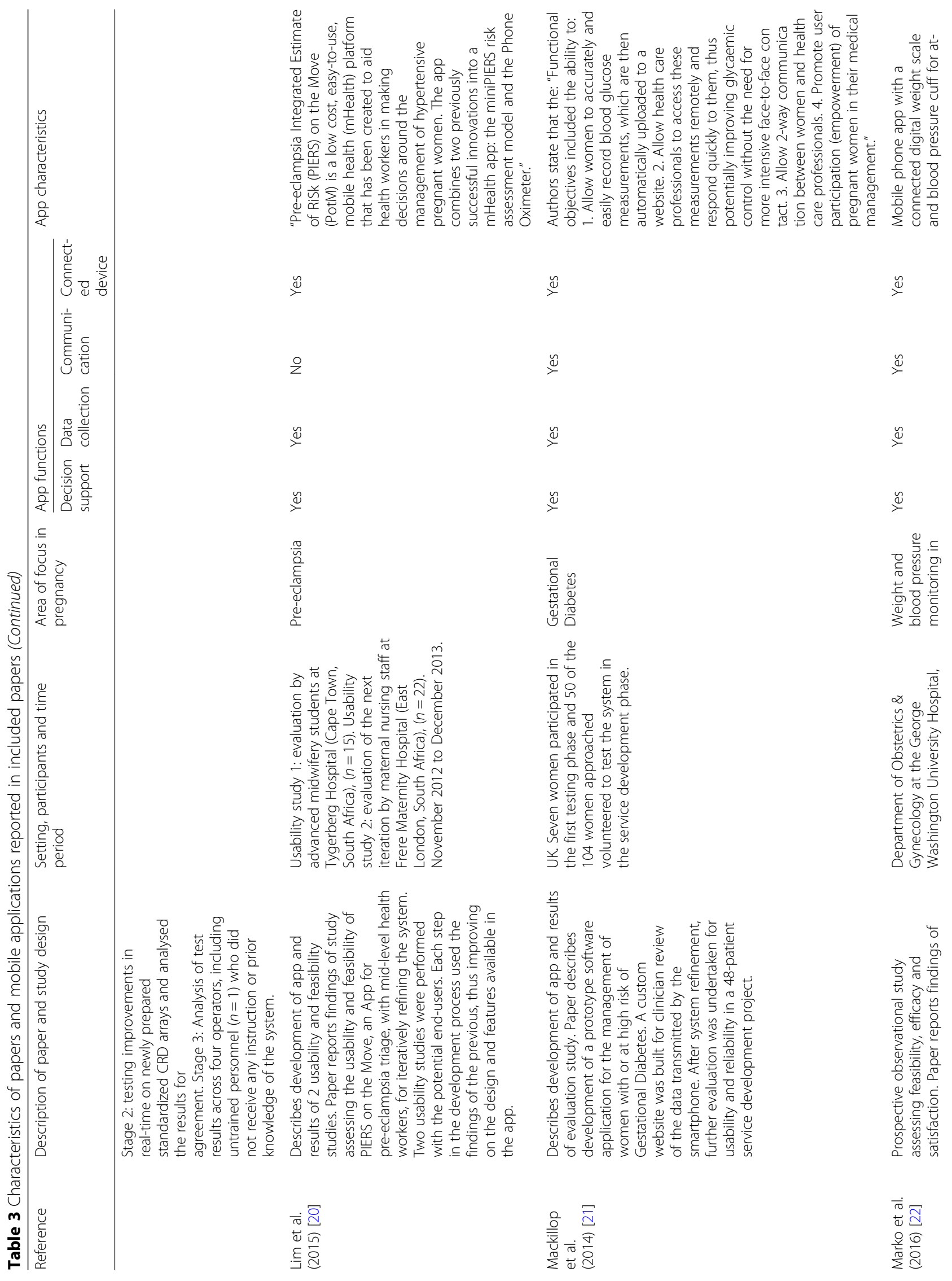



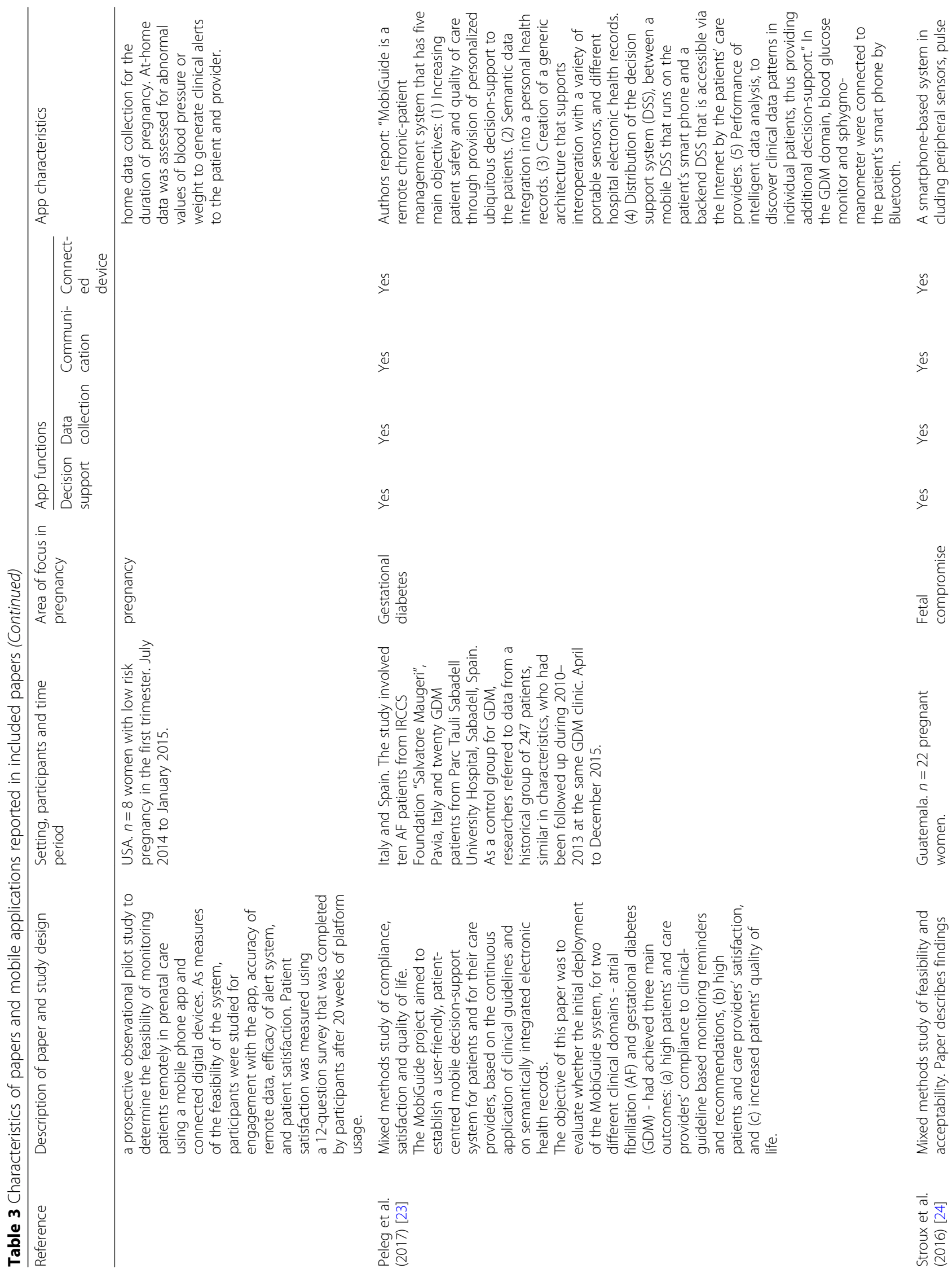

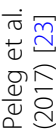




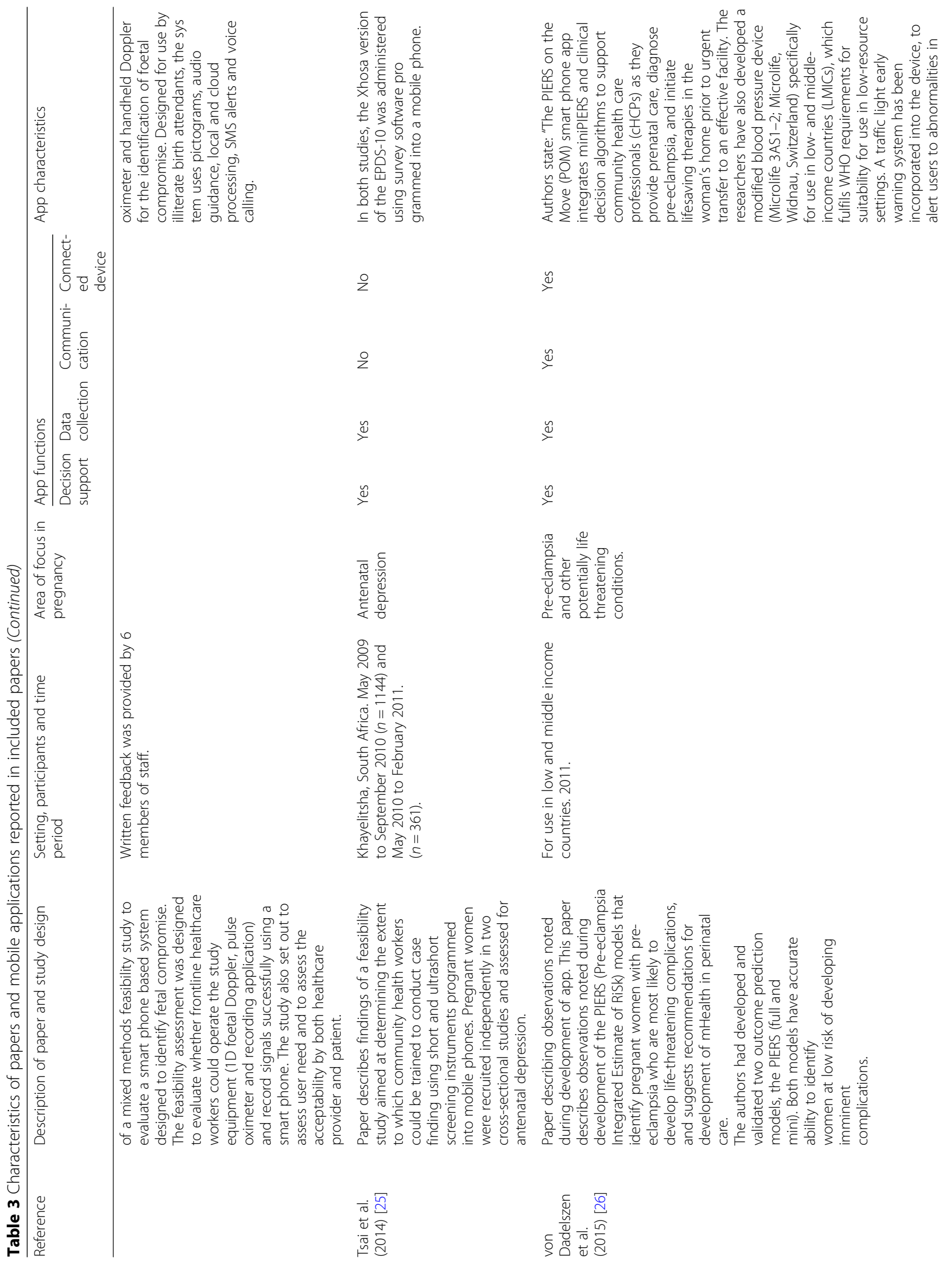




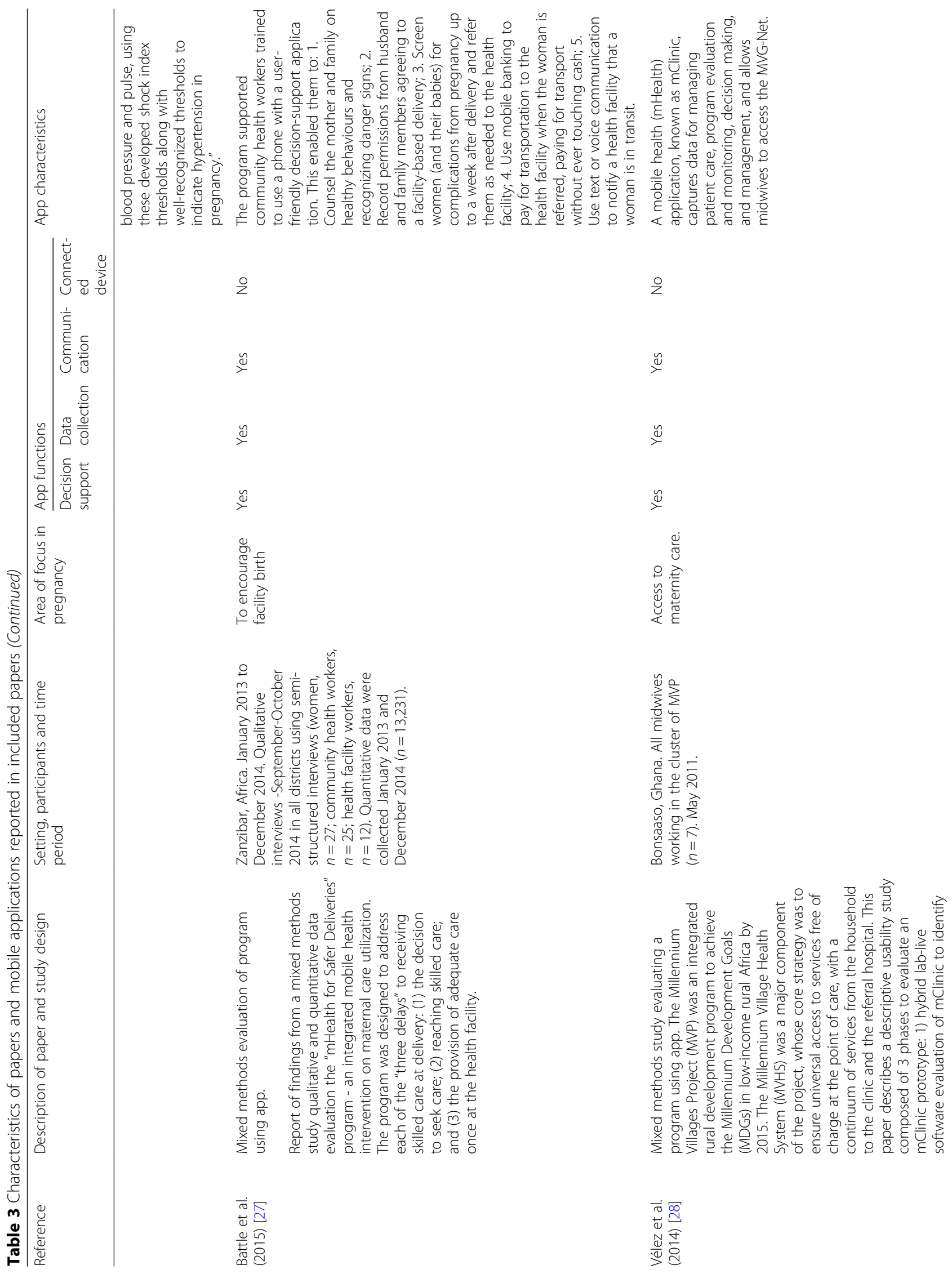




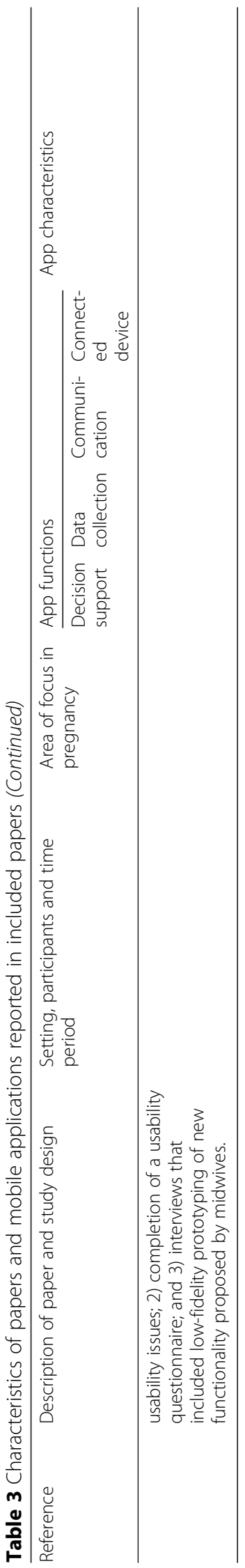


in the Congo Red Dot test to assess the presence of misfolded proteins in urine [19]. This test has been proposed as a possible diagnostic test for pre-eclampsia that could be particularly useful in low resource settings where more sophisticated laboratory facilities are unavailable.

Communication between patients and healthcare workers, or between healthcare workers and colleagues or other experts, was valued as an important element in the success of the projects in which the apps played a central role [17, 21, 27]. This appeared to be so whether the communication was carried out directly through the app, or simply by the user being able to communicate using the same device, i.e. mobile phone.

Data collection, validation, transfer and integration with other health records and research databases, and the ability to set alerts, as noted above, along with other integrated features of mobile phone technology, such as time stamping and Global Positioning System (GPS) tracking of phone location, were also noted as important and useful attributes because, for example, the time and place of the clinical visit could be recorded [17, 21, 23, 24, 28].

Delivering healthcare interventions through mobile technology also provided the opportunity to adapt programmes relatively easily to account for specific needs of the end-users. Accessibility was enhanced, e.g. picture and video instructions for illiterate users [24]. Language and cultural diversity issues were also relatively easily addressed and incorporated into different versions of the app [17, 21, 24].

\section{Theme 4: the importance of user involvement in development and evaluation}

The importance of user involvement in the development and evaluation of their app was emphasized in several papers $[17,20,26,28]$. The authors noted that this was not only a key step in enhancing the acceptability and usability of the device/programme, but also a mechanism by which they could foster engagement by local stakeholders, community leaders and healthcare funders. This interaction was recognised as part of the pathway to ensure acceptability of the programme and to maximize its chances of being sustained.

\section{Discussion}

This scoping review has identified and considered a number of relatively recent papers, mainly reporting early stage development and feasibility or acceptability studies designed to inform further development of the mobile app the paper was concerned with. The number of papers identified was relatively small compared to the number of medical apps readily available for download onto mobile devices. It is likely that many clinicians and other health care professionals are using them on an ad hoc basis. However, there are still only very few peerreviewed publications in high quality professional journals that can confirm their utility, reliability, effect on outcomes and successful implementation or scale up. None of the papers reported application for regulatory approval by either the FDA or MHRA.

It is possible that the search strategy employed may have missed some important papers due to the lack of standardised search terms associated with the relatively new field of mobile healthcare. The lack of unified language has been previously identified and efforts to address this made, such as the WHO "Classification of Digital Health Interventions" [29]. However, these are relatively recent, and may take some time to become apparent in the literature.

An extensive number of potentially eligible papers required a review of the full text because the nature of the decision support tool or mobile app was not clear from the title or abstract alone. In addition, the speed with which new papers are published makes efforts to undertake a truly comprehensive review of such a fast growing literature base challenging.

Our objectives were to: 1 ) determine the current landscape of mobile phone app use for clinical decision support in pregnancy; 2) identify perceived benefits and potential hazards of use and 3) identify facilitators and barriers to implementation of these apps into clinical practice. These objectives have largely been met through thematic analysis. The findings are consistent with the widely used "Theory of Acceptance Model" [30]. This model proposes that two particular beliefs, "perceived usefulness" and "perceived ease of use", are primarily important in predicting future use of computer software. It is, therefore, not surprising that the apps referred to in this review were generally considered acceptable. The issue of data security, however, briefly mentioned in two papers $[17,28]$ did not appear to be particularly important. Where it had been raised as a concern, password protection at app, rather than phone, level [28] and data encryption [17] appeared to provide acceptable solutions. This may become a more important issue in the future, however, following recent scandals regarding the misuse of personal online data [31].

This scoping review has considered papers reporting on mobile phone apps for clinical decision support in pregnancy. It appears that the body of literature relating to this precise area remains sparse and relatively recent. No papers were found of studies reporting effects on clinical outcomes, although the two papers on programmes to improve healthcare utilization reported success. It is expected, however, that more publications will follow in due course, as the papers reviewed were largely reporting results of feasibility studies of projects that will have entered later phases of development. The situation 
is also likely to improve in response to calls for the adoption of suitable monitoring and evaluation frameworks, part of the World Health Organisation's "Global Strategy on Digital Health 2020-2024", which is currently open for public consultation (April 2019) [32].

\section{Conclusion}

This review highlights the benefits of mobile apps for clinical decision support in pregnancy and potential barriers to implementation, but reveals a lack of rigorous reporting of evaluation of their use and data security. This situation may change, however, following the issue of FDA and MHRA guidelines and implementation of UK government and other international strategies. Overall, the findings suggest that ease of use, portability and multi-functionality make mobile apps for clinical decision support in pregnancy useful and acceptable tools for clinicians.

\section{Abbreviations}

App: Mobile or smartphone application; FDA: Food and Drugs

Administration (USA); MHRA: Medicines and Healthcare products Regulatory Agency (UK)

\section{Acknowledgements}

Not applicable.

\section{Authors' contributions}

JC, JS, AHS RMT made substantial contributions to conception and design of the review and drafting the manuscript. All authors were involved in revising the manuscript critically for important intellectual content and approving the final version. JC, JS, AHS and RMT agreed to be accountable for all aspects of the work in ensuring that questions related to the accuracy or integrity of any part of the work are appropriately investigated and resolved.

\section{Funding}

JC is supported by a National Institute for Health Research (NIHR) Clinical Academic Training Fellowship (CDRF-2013-04-026). JS is an NIHR Senior Investigator, and with AHS and RMT receives funding from the NIHR Biomedical Research Centre based at Guy's and St Thomas' NHS Foundation Trust and King's College London and the NIHR Collaboration for Leadership in Applied Health Research and Care South London at King's College Hospital NHS Foundation Trust. The funders had no role in the design of the study and collection, analysis, and interpretation of data or in writing the manuscript. The views expressed are those of the authors and not necessarily those of the National Health Service, the NIHR or the Department of Health and Social Care.

\section{Availability of data and materials}

All data generated or analysed during this study are included in this published article.

Ethics approval and consent to participate

Not applicable.

\section{Consent for publication}

Not applicable.

\section{Competing interests}

The authors declare that they have no competing interests.
Received: 29 May 2019 Accepted: 30 October 2019

Published online: 12 November 2019

\section{References}

1. Perera C. The evolution of E-health-mobile technology and mHealth. J Mobile Technol Med. 2012;1(1):1-2.

2. Department of Health and Social Care. "The future of healthcare: our vision for digital, data and technology in health and care" policy paper. 2019. Available online at: https://www.gov.uk/government/publications/thefuture-of-healthcare-our-vision-for-digital-data-and-technology-in-healthand-care/the-future-of-healthcare-our-vision-for-digital-data-and-technologyin-health-and-care. Accessed 14 Apr 2019

3. Amoakoh-Coleman M, Borgstein AB, Sondaal SF, Grobbee DE, Miltenburg AS, Verwijs M, Ansah EK, Browne JL, Klipstein-Grobusch K. Effectiveness of mHealth interventions targeting health care workers to improve pregnancy outcomes in low- and middle-income countries: a systematic review. J Med Internet Res. 2016;18(8):e226.

4. Kay M, Santos J, Takane M. mHealth: new horizons for health through mobile technologies. World Health Organ. 2011;64(7):66-71.

5. Sondaal SFV, Browne JL, Amoakoh-Coleman M, Borgstein A, Miltenburg AS, Verwijs M, Klipstein-Grobusch K. Assessing the effect of mHealth interventions in improving maternal and neonatal care in low- and middleincome countries: a systematic review. PLoS ONE. 2016;11(5):e0154664.

6. Bush J, Barlow DE, Echols J, Wilkerson J, Bellevin K. Impact of a mobile health application on user engagement and pregnancy outcomes among Wyoming Medicaid members. Telemed J E-Health. 2017;23(11):891-8.

7. Chen H, Chai Y, Dong L, Niu W, Zhang P. Effectiveness and appropriateness of mHealth interventions for maternal and child health: systematic review. JMIR mHealth uHealth. 2018;6(1):e7.

8. Arbour MW, Stec MA. Mobile applications for women's health and midwifery care: a pocket reference for the 21st century. J Midwifery Womens Health. 2018;63(3):330-4.

9. Payne KFB, Wharrad H, Watts K. Smartphone and medical related App use among medical students and junior doctors in the United Kingdom (UK): a regional survey. BMC Med Inform Decis Mak. 2012;12(1):121.

10. Perry $R$, Burns $R$, SimonFreeman R. A survey of mobile app use among California obstetrics and gynecology residents. In: 65th Annual Clinical and Scientific Meeting of the American College of Obstetricians and Gynecologists, ACOG 2017. United States. 129 (Supplement 1) (pp 95S); W.B. Saunders, Obstetrics and Gynecology. Conference; 2017.

11. Bierbrier R, Lo V, Wu RC. Evaluation of the accuracy of smartphone medical calculation apps. J Med Internet Res. 2014;16(2):e32.

12. Food and Drug Administration. Mobile medical applications: guidance for industry and Food and Drug Administration staff. 2015. Available online at: https://www.fda.gov/downloads/MedicalDevices/

DeviceRegulationandGuidance/GuidanceDocuments/UCM263366.pdf. Accessed 17 Aug 2018.

13. Medicines and Healthcare products Regulatory Agency. Guidance: medical device stand-alone software including apps (including IVDMDs). 2018. Available online at: https:/www.gov.uk/government/publications/medicaldevices-software-applications-apps. Accessed 17 Aug 2018.

14. Agarwal S, Perry HB, Long LA, Labrique AB. Evidence on feasibility and effective use of mHealth strategies by frontline health workers in developing countries: systematic review. Tropical Med Int Health. 2015;20(8): 1003-14.

15. Ritchie J, Spencer L. Qualitative data analysis for applied policy research. In: Bryman A, Burgess RG, editors. Analysing qualitative data. London: Routledge; 1994.

16. Watson HA, Carter J, Seed PT, Tribe RM, Shennan AH. The QUiPP app: a safe alternative to a treat-all strategy for threatened preterm labor. Ultrasound Obstet Gynecol. 2017;50(3):342-6.

17. Dunsmuir DT, Payne BA, Cloete G, Petersen CL, Gorges M, Lim J, von Dadelszen P, Dumont GA, Ansermino JM. Development of mHealth applications for pre-eclampsia triage. IEEE J Biomed Health Informatics. 2014;18(6):1857-64

18. Jeon E, Park H, Jo S, Kang H, Lee JY. Mobile apps providing tailored nursing interventions for patients with metabolic syndrome. Stud Health Technol Inform. 2016;225:510-4. https://doi.org/10.3233/978-1-61499-658-3-510.

19. Jonas SM, Deserno TM, Buhimschi CS, Makin J, Choma MA, Buhimschi IA. Smartphone-based diagnostic for preeclampsia: an mHealth solution for 
administering the Congo Red Dot (CRD) test in settings with limited resources. J Am Med Inform Assoc. 2016;23(1):166-73.

20. Lim J, Cloete G, Dunsmuir DT, Payne BA, Scheffer C, von Dadelszen P, Dumont GA, Ansermino JM. Usability and feasibility of PIERS on the move: an mHealth app for pre-eclampsia triage. JMIR mHealth uHealth. 2015;3(2):e37.

21. Mackillop L, Loerup L, Bartlett K, Farmer A, Gibson OJ, Hirst JE, Kenworthy Y, Kevat DA, Levy JC, Tarassenko L. Development of a real-time smartphone solution for the management of women with or at high risk of gestational diabetes. J Diabetes Sci Technol. 2014;8(6):1105-14.

22. Marko Kl, Krapf JM, Meltzer AC, Oh J, Ganju N, Martinez AG, Sheth SG, Gaba ND. Testing the feasibility of remote patient monitoring in prenatal care using a mobile app and connected devices: a prospective observational trial. JMIR Res Protoc. 2016;5(4):e200

23. Peleg M, Shahar Y, Quaglini S, Broens T, Budasu R, Fung N, Fux A, GarcíaSáez G, Goldstein A, González-Ferrer A. Assessment of a personalized and distributed patient guidance system. Int J Med Inform. 2017;101:108-30.

24. Stroux L, Martinez B, Coyote Ixen E, King N, Hall-Clifford R, Rohloff P, Clifford $\mathrm{GD}$. An mHealth monitoring system for traditional birth attendant-led antenatal risk assessment in rural Guatemala. J Med Eng Technol. 2016; 40(7-8):356-71.

25. Tsai AC, Tomlinson M, Dewing S, le Roux IM, Harwood JM, Chopra M, Rotheram-Borus MJ. Antenatal depression case finding by community health workers in South Africa: feasibility of a mobile phone application. Arch Womens Ment Health. 2014;17(5):423-31.

26. von Dadelszen P, Magee LA, Payne BA, Dunsmuir DT, Drebit S, Dumont GA, Miller S, Norman J, Pyne-Mercier L, Shennan AH, Donnay F, Bhutta ZA Ansermino JM. Moving beyond silos: how do we provide distributed personalized medicine to pregnant women everywhere at scale? Insights from PRE-EMPT. Int J Gynaecol Obstet. 2015;131(Suppl 1):S10-5.

27. Battle JD, Farrow L, Tibaijuka J, Mitchell M. mHealth for safer deliveries: a mixed methods evaluation of the effect of an integrated mobile health intervention on maternal care utilization. Healthcare. 2015;3(4):180-4.

28. Vélez O, Okyere PB, Kanter AS, Bakken S. A usability study of a mobile health application for rural Ghanaian midwives. J Midwifery Womens Health. 2014; 59(2):184-91.

29. WHO. Classification of Digital Health Interventions v 1.0: A shared language to describe the uses of digital technology for health. 2018. Available online at: https://www.who.int/reproductivehealth/publications/mhealth/ classification-digital-health-interventions/en/. Accessed 14 Apr 2019.

30. Davis FD, Bagozzi RP, Warshaw PR. User acceptance of computer technology: a comparison of two theoretical models. Manag Sci. 1989;35(8): 982-1003.

31. Cadwalladr C, Graham-Harrison E. Revealed: 50 million Facebook profiles harvested for Cambridge Analytica in major data breach. The Guardian. 2018;17:22.

32. WHO. Public Consultation on the Draft Global Strategy on Digital Health 2019. Online: https://extranet.who.int/dataform/183439. Accessed 27 Apr 2019.

\section{Publisher's Note}

Springer Nature remains neutral with regard to jurisdictional claims in published maps and institutional affiliations.

Ready to submit your research? Choose BMC and benefit from:

- fast, convenient online submission

- thorough peer review by experienced researchers in your field

- rapid publication on acceptance

- support for research data, including large and complex data types

- gold Open Access which fosters wider collaboration and increased citations

- maximum visibility for your research: over $100 \mathrm{M}$ website views per year

At BMC, research is always in progress.

Learn more biomedcentral.com/submissions 